\title{
Trabalho "porco, perigoso e pesado" dos dekasseguis e incidência de doenças psíquicas
}

CIBELE CRISTINA OSAWA*

GAlimbertTI, Percy.

O caminho que o dekassegui sonhou (Dekassegui no yumê-ji):

cultura e subjetividade no movimento dekassegui.

São Paulo: Educ, 2002.

Prefácio: Lili Kawamura

O caminho que o dekassegui sonhou (Dekassegui no yumê-ji): cultura e subjetividade no movimento dekassegui foi realizado com base na experiência e vivência clínica em Medicina Psiquiátrica de Percy Galimbertti e é fruto de seu trabalho de conclusão de mestrado em Ciências Sociais pela Universidade Católica de São Paulo (PUC-SP), apresentado em agosto de 2000.

O livro é composto por sete capítulos, além de elementos pré-textuais (prefácio, apresentação e outros) e pós-textuais (epílogo, referências bibliográficas, anexo e glossário de termos japoneses). Nos capítulos iniciais, o autor contextualiza o estudo e faz um levantamento dos elementos para a compreensão do que virá a seguir: estudo de casos, expostos de forma sucinta e ao mesmo tempo dinâmica, e delineamento da relação existente entre a migração dekassegui e o sofrimento emocional constatado na população estudada.

Durante a atuação profissional de Galimbertti no norte paranaense, mais precisamente nas cidades de Maringá e Londrina, entre os anos de 1991 e 2000, foi atendida, tanto pelo serviço público, como em seu consultório particular, uma parcela significativa de descendentes de japoneses que apresentavam sofrimento emocional e similaridades nos seus relatos: trabalharam como dekasseguis.

Segundo o autor, no contexto nipo-brasileiro entende-se por dekasseguis os japoneses radicados no Brasil, ou seus descendentes até a terceira geração, que viajam ao Japão para trabalhar por períodos de tempos variados. 
Após o retorno dos dekasseguis ao Brasil, ocorreu o desencadeamento de sofrimento emocional muito intenso no momento da primeira consulta, traduzido como: manifestações somáticas, ansiedades, transtornos de humor, ansiedade, insônia, angústias, depressões, isolamento, irritação, agressividade, alcoolismo, uso de drogas e distúrbios de percepção (como falsas percepções e idéias delirantes, especialmente de caráter persecutório). Tais sintomas extravasaram os limites do suportável e do denominado "limiar nikkey" de tolerância, requerendo assistência médica. Em geral, a população estudada apresenta maior tolerância a algumas "situações de sofrimento" do que a maioria da população.

Para fins de conceituação, nikkey é a pessoa de origem japonesa, qualquer que seja sua geração e são designados termos específicos aos descendentes de japoneses, dependendo da geração em que se situam. Denominam-se isseys, nisseys e sanseys, respectivamente, para nikkeys de primeira, segunda e terceira geração.

Legalmente, a imigração de descendentes de japoneses para executar trabalhos pouco qualificados no Japão se deu a partir de 1991. A população local, de alto nível de instrução, opta por trabalhos técnicos e específicos, o que resulta na necessidade de mão-de-obra imigrante para os trabalhos indesejáveis. Paralelamente, no fim dos anos 80 e início da década de 1990, o Brasil passava por um processo extremamente penoso de mudança de moeda e hiperinflação, resultando na desvalorização da força de trabalho e descapitalização dos salários. Essa situação favoreceu o movimento dekassegui.

Outras motivações que impulsionam a migração são de caráter cultural, relacionadas com sua etnia, modo de vida e tradições. Galimbertti (2002) relatou que $46 \%$ da população estudada alegaram motivo econômico, enquanto que $35 \%$ se sentiram atraídos por fatores econômicos aliados a culturais. É fato que a maioria dos dekasseguis vivia bem no Brasil, com nível de conforto maior do que a grande maioria dos brasileiros não-nikkeys. Cerca de 50\% da população brasileira ganhava entre 1 e 5 salários mínimos, enquanto $20 \%$ da população nikkey recebia essa faixa salarial, sendo que o restante tinha renda superior a isso (YOSHINO, 1996 apud GALIMBERTTI).

A metodologia de pesquisa do autor foi delimitada nas cidades de Londrina e Curitiba no período de 1996 e 1999. Dispôs-se de métodos qualitativos e demográficos, fundamentados em anamneses, acompanhamentos no mínimo semanais, entrevistas periódicas e anotações. O uso de gravador não foi adotado 
por constranger os pacientes. As cidades estudadas representam a maior concentração de nikkeys do estado do Paraná, sendo que 3,6\% da população de Londrina é nikkey.

Modestamente, o autor avisa de antemão que não teve a pretensão de esgotar o estudo da cultura japonesa, mas de estimular o aprofundamento dos interessados na pesquisa. Porém, a contextualização do estabelecimento da cultura nipônica, além da abordagem dos efeitos da globalização na necessidade de mão-de-obra estrangeira, é um dos pontos fortes do trabalho e peça-chave para o entendimento da relação existente entre a migração para o Japão e o adoecimento.

Somado-se a isso, é bastante compreensível e lógico o raciocínio proposto pelo autor, ao sugerir as causas, e não apenas uma única, que impulsionaram o abalo emocional dos dekasseguis. Não se trata apenas do fator econômico, mas da junção de vários outros fatores. Segundo as modernas conceituações de saúde, que incluem o usufruto de condições reais de conforto físico e mental, habitação, trabalho e afeto, é possível evidenciar a influência de fatores múltiplos, sejam biológicos ou sociais, na gênese das doenças e distúrbios psíquicos.

Os tópicos, em geral, foram muito bem abordados, com depoimentos marcantes (capítulo 6), o que facilita o entendimento do nexo causal entre a migração ao Japão, o retorno ao Brasil e o aparecimento dos sintomas de doenças psicossomáticas.

As motivações que conduziram ao trabalho no Japão, sejam objetivas ou subjetivas, são apontadas como "[...] muitas vezes mais fortes que suas condições psicológicas, o que tem levado um número muito grande desses trabalhadores a sofrer desconfortos emocionais durante sua estada no Japão e/ ou seu retorno ao Brasil, com comprometimentos, muitas vezes, graves [...]" (p. 135). Em determinados casos, houve a necessidade de buscar recursos financeiros no Japão, dada a instabilidade econômica brasileira e ausência de moeda forte. No período avaliado, o Real ainda não estava em vigor.

Ao migrar, os dekasseguis se abalaram com a mudança para uma cultura significativamente distinta da cultura ocidental. Alguns não estavam familiarizados com o idioma japonês e até mesmo desconheciam seu paradeiro ou ocupação no Japão. Na permanência no Japão, a inadaptação à cultura oriental, as dificuldades de adaptação, a discriminação e segregação, assim 
como a desambientalização na volta ao Brasil foram mencionados como contribuintes do quadro clínico em tese.

A desestruturação do ambiente familiar foi relatada em alguns casos. Alguns se separaram da família, deixando cônjuges e filhos pequenos no Brasil. Em determinado relato, no retorno ao país de origem, o filho não reconheceu o dekassegui como figura paterna e o rejeitou por tempo considerável, causando certo desconforto psicológico ao migrante. Em outro, uma entrevistada do sexo feminino perdeu o pai, que faleceu no Brasil por motivos de saúde, durante sua estada no Japão como dekassegui. Isso provocou nela um sentimento de frustração, por não ter sido possível cuidar do pai, o que ela considerou como tarefa feminina que não pôde cumprir. Aqui merece destaque a questão de gênero e o comprometimento com os papéis desempenhados na sociedade.

Como o fenômeno dekassegui pode ser entendido por algumas pessoas como ascensão social por parte de indivíduos de descendentes de japoneses e seus cônjuges, um caso particular foi retratado. Um dos entrevistados confessou se sentir traído e vítima de golpe de mulher de origem não-nipônica, com quem contraiu laços matrimoniais, para conseguir o visto de ingresso no Japão em busca de melhores oportunidades de vida. Aqui, o sentimento de traição pelo casamento desfeito após a chegada ao Japão pode ser interpretado tanto como neurose (consequiência), como fato desencadeador (causa) de outros distúrbios psíquicos.

Quanto às questões comportamentais dos dekasseguis, há indícios de isolamento do convívio social, descrito como "[...] muitos acumulam silenciosos sofrimentos que fragilizam seus egos, comprometem seu emocional, sua capacidade psíquica, comprometem sua capacidade laborativa e de interrelacionamento com a sociedade. Perdendo sua capacidade laborativa ou reduzindo sua 'produtividade', tornam-se, então, descartáveis, ficando sem atenção para seus sofrimentos [...]" (p. 38).

O compromisso de economizar dinheiro e trabalhar arduamente para o retorno antecipado ao Brasil também foi mencionado. Dentre os exemplos, cônjuges trabalhando em turnos distintos não conseguiram conviver em harmonia, optando pela separação, o que desencadeou depressão e outros transtornos mentais.

Com relação às condições de trabalho, habitação e alimentação, faltaram subsídios à multiplicidade de fatores no estabelecimento do nexo causal 
do adoecer. Particularmente no que se refere à ocupação, a análise poderia ter sido mais ampla e não apenas sutil, considerando os sintomas/doenças psíquicas como acidentes do trabalho.

Acidente do trabalho, segundo o Decreto ${ }^{\circ} 2.172$, de 5 de março de 1997, é o que ocorre pelo exercício do trabalho a serviço da empresa, ou ainda pelo exercício do trabalho dos segurados especiais, provocando lesão corporal ou perturbação funcional que cause a morte ou a perda ou redução da capacidade para o trabalho permanente ou temporário. São considerados acidentes de trabalho: i) a doença profissional: aquela adquirida ou desencadeada pelo exercício do trabalho peculiar a determinada atividade; e, ii) a doença do trabalho: aquela adquirida ou desencadeada em função das condições especiais em que o trabalho é realizado e que com ele se relacione diretamente (BELLUSCI, 2002, p. 9).

Quanto à ocupação, os trabalhos executados no Japão são muito diferentes dos que os dekasseguis estão acostumados no Brasil. Isso possivelmente porque $38 \%$ dos dekasseguis interrogados possuíam curso superior completo e $76 \%$ tinham pelo menos o nível médio. Em geral, os trabalhos dos dekasseguis no Japão são indesejáveis e não qualificados, constituindo os "três kkk", isto é, kitanai, kiken e kitsui, o que pode ser traduzido em português como os "três ppp": 'porco' (aqui o autor preferiu usar o termo 'sujo'), perigoso e pesado. Diz-se que o trabalho era estressante, a jornada diária de trabalho era composta em média por 10,2 horas e $90,8 \%$ dos dekasseguis trabalhavam aos sábados.

De modo geral, as indústrias japonesas empregadoras de dekasseguis se baseiam no modelo de produção automatizado denominado fordismo (LACAZ, 2000). Nele, o trabalho é realizado em grupo, com uma divisão minuciosa das tarefas. Cada funcionário executa exaustivamente uma única função ao longo do seu turno de trabalho. Não há a necessidade de treinamento e as regras a serem obedecidas são bem elaboradas, com o intuito de criar produtos padronizados.

Esse modelo, caracterizado pela monotonia e repetição de movimentos, pode acarretar agravos à saúde do trabalho, particularmente no que se refere ao campo de estudo da Ergonomia (IIDA, 1990). Como pode surgir insatisfação por causa da inadequação ergonômica do trabalho e da estrutura de personalidade, o que conduz ao sofrimento mental e até a síndromes 
psicopatológicas caracterizadas (BELLUSCI, 2002), também mereciam destaque:

- a avaliação da jornada de trabalho, possivelmente desgastante, impulsionada pelo pagamento de horas-extras, e o trabalho em turnos, interferindo no ritmo circadiano (vigília-sono);

- a verificação da existência ou não de organização do trabalho, com o estabelecimento de pausas (IIDA, 1990), concomitantemente ao preconizado pelo Anexo $\mathrm{n}^{\mathrm{o}} 3$ da Norma Regulamentadora (NR) do trabalho $\mathrm{n}^{\circ} 15$, de acordo com o tipo de atividade e a temperatura de exposição (MANUAIS..., 2006). As características da organização do trabalho determinam sua divisão, o conteúdo da tarefa, o trabalho repetitivo, o sistema hierárquico, as modalidades de comando, as relações de poder, a responsabilidade, os salários, os prêmios por produção e outros (BELLUSCI, 2002);

- a caracterização do ambiente físico, avaliando os riscos físicos (temperatura, vibração, pressão, barulho, irradiação, altitude), químicos (presença de vapores, gases, poeiras, fumaças), biológicos (microrganismos, parasitas) e ergonômicos (IIDA, 1990; BELLUSCI, 2002; MENDES, 2005);

- a adequação dos postos de trabalho às características antropométricas dos dekasseguis (GOMES FILHO, 2003);

- a constatação da síndrome de Burnout, caracterizada por exaustão emocional, despersonalização e sentimento de pouca realização e satisfação pessoal. O quadro clínico se dá pela perda do autocontrole emocional, irritabilidade, agressividade, perturbações do sono e manifestações depressivas (ROCHA; GLIMA, 2002). Tais sintomas foram verificados nos pacientes estudados, porém não foram denominados por esse termo técnico; e,

- a conceitualização do assédio moral (O QUE É ASSÉDIO MORAL?, 2005), exercido pelos empreiteiros. O estudo de caso $n^{\circ} 3$ (capítulo 6) é caracterizado por ameaças e constrangimentos corriqueiros por parte do empreiteiro aos dekasseguis, o que constitui assédio moral.

Apesar de não ter focado as condições de trabalho dos dekasseguis (os "três ppp") e sua relação direta com os acidentes de trabalho citados, a 
obra é de grande valia científica, do ponto de vista histórico e sociocultural. Há nela a contextualização do movimento dekassegui e as razões correlatas do adoecer.

Para reforçar a grandiosidade do trabalho de Galimbertti e sua significativa contribuição aos estudos epidemiológicos de segurança e saúde no trabalho, que também devem ser baseados no ser humano como um ser complexo, provido de características étnicas, culturais, psíquicas e comportamentais, o livro conta com o prefácio de Lili Kawamura, profissional de experiência comprovada sobre a temática do trabalho dos dekasseguis e autora da obra Para onde vão os brasileiros? (KAWAMURA, 2003).

Em síntese, O caminho que o dekassegui sonhou é leitura indispensável para os profissionais de segurança e saúde do trabalho, tendo em vista a multiplicidade de fatores relacionados à constatação de acidentes do trabalho, doenças profissionais ou doenças do trabalho. Aos interessados em saber mais sobre o movimento dekassegui e a cultura nipônica, é um excelente ponto de partida.

De forma clara, concisa e sucinta, os relatos de Galimbertti são dignos de mérito, prestígio e reconhecimento. É uma dissertação que não tenta impressionar pelo uso de termos técnicos apenas acessíveis a profissionais da área. Por outro lado, ela impressiona pela riqueza dos relatos, seqüência lógica dos capítulos, leitura acessível, agradável e eloqüente e pela seriedade do trabalho desenvolvido, sem expor demasiadamente os entrevistados ou gerar sensacionalismo.

Todos os candidatos a dekassegui deveriam apreciar essa obra antes de seu rumo ao Japão, a fim de se conscientizarem dos possíveis adoecimentos a que estão sujeitos nessa experiência profissional e cultural. 


\section{Referências}

BELLUSCI, S. M. Doenças profissionais ou do trabalho. 4. ed. São Paulo: Senac, 2002. 99 p.

GALIMBERTTI, P. O caminho que o dekassegui sonhou (Dekassegui no yumê-ji): cultura e subjetividade no movimento dekassegui. São Paulo: Educ, $2002.234 \mathrm{p}$.

GOMES FILHO, J. Ergonomia do objeto: sistema técnico de leitura ergonômica. São Paulo: Escrituras, 2003. 255 p.

IIDA, I. Ergonomia, projeto e produção. 5. reimp. São Paulo: Edgard Blücher, $1998.465 \mathrm{p}$.

KAWAMURA, L. Para onde vão os brasileiros? 2. ed. rev. Campinas: Unicamp, 2003. 268 p.

LACAZ, F. A. C. Qualidade de vida no trabalho e saúde/doença. Ciência \& Saúde Coletiva, Rio de Janeiro, v. 5, n. 1, p. 151-161, 2000.

MANUAIS de legislação Atlas de segurança e medicina do trabalho. 58. ed. São Paulo: Atlas, 2006. 636 p.

MENDES, R. Patologia do trabalho. v. 1. 2. ed. São Paulo: Atheneu, 2005. $986 \mathrm{p}$.

O QUEÉASSÉDIO MORAL? Disponível em: <http://www.assediomoral.org/ site/assedio/AMconceito.php>. Acesso em: 27 dez. 2005.

ROCHA, L. E.; GLIMA, D. M. R. Distúrbios psíquicos relacionados ao trabalho. In: FERREIRA JÚNIOR, M. (Org.). Saúde no trabalho: temas básicos para o profissional que cuida da saúde dos trabalhadores. São Paulo: Roca, 2002. p. 320-348.

YOSHINO, N. L. Trabalho e saúde de migrantes japoneses (dekasseguis) no Japão. 1996. Dissertação (Mestrado em Saúde Pública) - Faculdade de Saúde Pública, Universidade de São Paulo, São Paulo, 1996 apud GALIMBERTTI, P. O caminho que o dekassegui sonhou (Dekassegui no yumê-ji): cultura e subjetividade no movimento dekassegui. São Paulo: EDUC, 2002. 234 p. 
RESENHAS E CRÍTICAS BIBLIOGRÁFICAS

\section{NOTA}

* Engenheira de Alimentos e de Segurança do Trabalho; mestre e doutoranda do Departamento de Tecnologia de Alimentos, Faculdade de Engenharia de Alimentos da Universidade Estadual de Campinas. Endereço eletrônico: cibele_osawa@yahoo.com.br. 